\title{
Serum Concentrations of Selenium and Copper in Patients Diagnosed with Pancreatic Cancer
}

Marcin R. Lener, $\mathrm{PhD}^{1}$
Rodney J. Scott, PhD²
Anna Wiechowska-Kozłowska, MD, $\mathrm{PhD}^{3}$
Pablo Serrano-Fernández, PhD ${ }^{1}$
Piotr Baszuk, MSc ${ }^{1}$
Katarzyna Jaworska-Bieniek, $\mathrm{PhD}^{1}$
Grzegorz Sukiennicki, MSc ${ }^{1}$
Wojciech Marciniak, MSc ${ }^{4}$
Magdalena Muszyńska, MSc ${ }^{4}$
Józef Kładny, MD, PhD
Tomasz Gromowski, MSc ${ }^{1}$
Katarzyna Kaczmarek, MSc ${ }^{1}$
Anna Jakubowska, $\mathrm{PhD}^{1}$
Jan Lubiński, MD, $\mathrm{PhD}^{1,4}$

${ }^{1}$ Department of Genetics and Pathology, International Hereditary Cancer Center, Pomeranian Medical University, Szczecin, Poland, ${ }^{2}$ Discipline of Medical Genetics, School of Biomedical Sciences, Faculty of Health, University of Newcastle and The Hunter Medical Research Institute, Newcastle, New South Wales, Australia, ${ }^{3}$ Laboratory of Endoscopy, Division of Heath Care Ministry of Internal Affairs and Administration, Szczecin, ${ }^{4}$ Read-Gene S.A. Grzepnica, ${ }^{5}$ Department of General and Oncological Surgery, Pomeranian Medical University, Szczecin, Poland

Correspondence: Marcin R. Lener, PhD Department of Genetics and Pathology, International Hereditary Cancer Center, Pomeranian Medical University, Połabska 4, 70-115 Szczecin, Poland

Tel: 48-91-466-1532

Fax: 48-91-466-1533

E-mail: marcinlener@poczta.onet.pl

Received July 27, 2015

Accepted December 16, 2015

Published Online December 28, 2015

\section{Purpose}

Understanding of the etiology and pathogenesis of pancreatic cancer ( $\mathrm{PaCa})$ is still insufficient. This study evaluated the associations between concentrations of selenium (Se) and copper $(\mathrm{Cu})$ in the serum of PaCa patients.

\section{Materials and Methods}

The study included $100 \mathrm{PaCa}$ patients and 100 control subjects from the same geographical region in Poland. To determine the average concentration of $\mathrm{Se}, \mathrm{Cu}$, and ratio $\mathrm{Cu}$ :Se in the Polish population, assay for Se and Cu was performed in 480 healthy individuals. Serum levels of Se and Cu were measured using inductively coupled plasma mass spectrometry.

Results

In the control group, the average Se level was $76 \mu \mathrm{g} / \mathrm{L}$ and $\mathrm{Cu} 1,098 \mu \mathrm{g} / \mathrm{L}$. The average Se level among PaCa patients was $60 \mu \mathrm{g} / \mathrm{L}$ and the mean Cu level was 1,432 $\mu \mathrm{g} / \mathrm{L}$. The threshold point at which any decrease in Se concentration was associated with PaCa was 67.45 $\mu \mathrm{g} / \mathrm{L}$. The threshold point of $\mathrm{Cu}$ level above which there was an increase in the prevalence of PaCa was 1,214.58 $\mu \mathrm{g} / \mathrm{L}$. In addition, a positive relationship was observed between increasing survival time and Se plasma level.

\section{Conclusion}

This retrospective study suggests that low levels of Se and high levels of Cu might influence development of $\mathrm{PaCa}$ and that higher levels of Se are associated with longer survival in patients with PaCa. The results suggest that determining the level of Se and Cu could be incorporated into a risk stratification scheme for the selection and surveillance control examination to complement existing screening and diagnostic procedures.

Key words

Selenium, Copper, Pancreatic neoplasms, Retrospective studies 


\section{Introduction}

Pancreatic cancer $(\mathrm{PaCa})$, the eighth most commonly diagnosed cancer in the developed world, has one of the worst prognoses of any malignancy with $98 \%$ succumbing to their disease within 5 years. Light is beginning to be shed on the underlying molecular events involved in development and progression of $\mathrm{PaCa}[1]$ but there is little information on the risk factors associated with disease.

Risk factors for $\mathrm{PaCa}$ include environmental exposure (such as cigarette smoking and excessive alcohol intake), type 2 diabetes (T2D) and genetic factors. Both smoking and T2D increase PaCa risk by about double [2-4]. Germline mutations in several genes: BRCA2, PALB2, CDKN2A, ATM, STK11, PRSS1, SPINK1, TP53, SMAD4, ARID1A, ROBO2, $K D M 6 A, P R E X 2$, and DNA mismatch repair have also been associated with an increased risk of disease [1,5]. In addition, two recently completed genome-wide association studies, PanScan1 and PanScan2, reported variants in ABO (rs505 922), 1q32.1 (rs3790844), 13q22.1 (rs9543325), and 5p15.3 (rs401681), which are associated with modestly increased risk of $\mathrm{PaCa}[6,7]$. Familial associations of $\mathrm{PaCa}$ are rare and cannot account for the frequency of disease, although if three first-degree relatives are affected, disease risk can be increased over 30 times [8].

The important role of micronutrients in the pathogenesis of malignancy is not fully understood, but must include both selenium (Se) and copper $(\mathrm{Cu})$. Both micronutrients are involved in many biochemical processes including cellular respiration, cellular utilization of oxygen, DNA and RNA production, maintenance of cell membrane integrity, and sequestration of free radicals [9]. In general, in relation to malignancy many studies suggest that Se supplementation can reduce not only the incidence of disease but also mortality [10]. Data from a meta-analysis of 49 prospective studies confirmed a reduction in cancer mortality, by $45 \%$ in persons with an optimized Se concentration [11].

The chemo-preventative benefit of Se may differ between individuals and the same dose may not be optimal for all. The preventative effect of Se supplementation strongly depends on the baseline levels of Se and is beneficial only for individuals with a low serum Se concentration. In terms of health benefit, the efficacy of Se is related to a "U" shaped curve [12]. Low levels of Se are associated with an increased risk of malignancy whereas too much (selenosis) is linked to an increased occurrence of common diseases, including T2D [13].

In cancer and inflammation, plasma $\mathrm{Cu}$ and ceruloplasmin concentrations rise and the rates of synthesis and secretion of ceruloplasmin by the liver are enhanced. The elevated ceruloplasmin concentrations in both of these conditions would provide additional $\mathrm{Cu}$ uptake by cells in normal tissues and as well as cancer cells. In addition, transcuprein (another Cu-binding protein) appears to be increased in malignancy. Ready uptake of $\mathrm{Cu}$ from non-ceruloplasmin fractions of plasma, which together account for the relatively high levels of $\mathrm{Cu}$ in tumor cells, has been demonstrated in neoplastic cells. $\mathrm{Cu}$ also plays a role in angiogenesis, a requirement for tumor growth, which may be mediated by Cu-dependent amine oxidases [14].

Higher Se levels were observed among healthy subjects both in regards to the patients with $\mathrm{PaCa}$, and those with chronic pancreatitis. However, patients with chronic pancreatitis had higher serum Se levels compared with those observed in PaCa patients. Simultaneously an inverse observation was observed for serum $\mathrm{Cu}$ levels, where $\mathrm{PaCa}$ patients had the highest levels of serum $\mathrm{Cu}$ [15]. Taken together, this suggests that serum $\mathrm{Se}$ and $\mathrm{Cu}$ levels are required for the progression of pancreatic disease.

It has yet to be determined whether altered $\mathrm{Se}$ and $\mathrm{Cu}$ concentrations are the cause or effect of malignancy. Hence, the utility of serum Se and $\mathrm{Cu}$ evaluation for cancer prevention, detection, monitoring treatment, and prognosis requires further investigation.

In the current study, we examined the levels of Se and $\mathrm{Cu}$ in PaCa patients and compared this to a healthy age-matched population from the same geographical region in Poland.

\section{Materials and Methods}

\section{Study participants}

A total of 100 PaCa patients and 100 aged-matched healthy control subjects were enrolled in the study after providing informed consent. Patients with clinically advanced $\mathrm{PaCa}$ were diagnosed and enrolled in the study at the Hospital of the Ministry of Internal Affairs and Administration in Szczecin between February 2011 and October 2014. For each $\mathrm{PaCa}$ patient included an unaffected individual registered at the International Hereditary Cancer Center, Pomeranian Medical University of Szczecin, was included as a control subject. Control subjects were part of a population-based study of the 1.3 million inhabitants of Poland designed to identify familial aggregations of cancer conducted by our center. Participants were matched for year of birth ( \pm 3 years), sex, smoking status (expressed in pack-years), and the total number of $\mathrm{PaCa}$ and any other malignancies among first degree relatives. All patients had a histopathological diagnosis of PaCa. The characteristics of the individuals included in the study are shown in Table 1. In addition, to determine 
the average concentration of $\mathrm{Se}, \mathrm{Cu}$, and ratio of copper to selenium levels ( $\mathrm{Cu}: \mathrm{Se}$ ) in the Polish population, 480 healthy individuals were assayed for Se and $\mathrm{Cu}$. The study was conducted in accordance with the Declaration of Helsinki and all participants signed an informed consent document prior to donating a blood sample. The study was approved by the Ethics Committee of Pomeranian Medical University in Szczecin under the number KB-0012/73/10. Each person enrolled in the study donated $\sim 10$ blood for sufficient serum for isolation and examination for the elements $\mathrm{Se}$ and $\mathrm{Cu}$ and $\sim 10 \mathrm{~mL}$ ethylenediaminetetraacetic acid blood for DNA isolation and for performance of genotyping. None of the study participants were taking any dietary supplements and donated to research while in the fasted state.

\section{Measurement of Se and $\mathrm{Cu}$ level}

The levels of Se and $\mathrm{Cu}$ in the serum were determined by Inductively Coupled Plasma Mass Spectrometry (ICP-MS, Elan DRC-e, PerkinElmer, Wellesley, MA). To validate the measurements a reference solution ("Seronorm" Serum Control for trace elements level I ClinCheck, Recipe) was measured every six samples in order to maintain the sensitivity and specificity of the assays. Cases and control subjects were tested alternately. The mean drift was used as a correction value for the samples, whereas a measured drift larger than $5 \%$ from the reference material caused recalibration of the device and re-measurement of the previous samples. A calibration curve was prepared using standard grade purity multi-element ICP-MS at a concentration of $1,000 \mu \mathrm{g} / \mathrm{L}$ (PerkinElmer). The pattern to working concentration (100 $\mu \mathrm{g} / \mathrm{L}$ ) was diluted with $1 \%$ nitric acid solution purity class Suprapur (Merck, Darmstadt, Germany) prepared in ultrapure deionized water with a resistance of $>18 \mathrm{M}$. The working solution standard serial dilution was then performed, which provided the reagents for use in performance of the calibration at $0.1,1,5$, and $10 \mu \mathrm{g} / \mathrm{L}$ (for measurement of Se) and $0.1,1,5,10,100$, and $200 \mu \mathrm{g} / \mathrm{L}$ (measured Cu). The correlation coefficient for each curve was $\geq 0.999$. Test samples and reference materials were prepared immediately before measurement. Samples were diluted 100 -fold, using a $1 \%$ solution of Suprapur (Merck). Nitric acid was prepared in ultrapure deionized water with a resistance of $>18 \mathrm{M}$.

\section{Statistical analysis}

The association between different categorical levels of $\mathrm{Se}, \mathrm{Cu}$, and disease status were evaluated by estimating odds ratios (OR) with 95\% confidence intervals (CI) from 2-by-2 contingency tables. The Fisher exact test was applied to determine whether or not the differences in proportions were statistically significant. For these estimates, individuals were
Table 1. Characteristics of individuals for pancreatic cancer study

\begin{tabular}{|lcc|}
\hline Characteristic & Case $(\mathbf{n}=\mathbf{1 0 0})$ & Control $(\mathbf{n = 1 0 0})$ \\
\hline Birth year range & $1930-1976$ & $1928-1978$ \\
\hline Age at sample, mean (range, yr) & $63.40(35-84)$ & $63.45(33-85)$ \\
\hline Sex & & \\
$\quad$ Male & 59 & 59 \\
\hline Female & 41 & 41 \\
\hline First-degree relatives & & \\
$\quad$ With pancreatic cancer & 4 & 4 \\
\hline Another cancer site & 43 & 43 \\
\hline Smoking status & & \\
$\quad$ Smoker & 27 & 73 \\
$\quad$ Non-smoker & 27 & 73 \\
\hline Pack-years, mean (range) & $28.99(2-50)$ & $26.14(2-50)$ \\
\hline
\end{tabular}

assigned to one of four categories, based on the distribution of microelement levels in both tested groups, corresponding to quartiles. The reference quartile category was that which included the largest number of controls, analogous to the standard procedure.

In addition, to improve the degree of detail, ORs were calculated and displayed graphically using a standard sliding windows approach. Overlapping windows (smoothing factor, 30 observations) slide over the range of microelement levels and OR was calculated for each one separately taking the expected proportion of controls and cases (1:1) as a reference and comparing with the observed proportion. A Lowess-regression was applied to these calculated data points to estimate the underlying $\mathrm{PaCa}$ incidence curve. If the OR could not be estimated (e.g., for the highest proportions of $\mathrm{Cu}$ to Se, where there are no controls, just cases, for the overlapping windows) OR was conservatively estimated to be the same as the last calculated OR. Such ORs were marked with a black/grey color to avoid confusion. The potential association between Se levels and survival time was assessed following a generalized linear model, where the covariates age, sex, pack-years and survival status were used for adjustment. Due to the limited sample size, interaction effects were not considered. All calculations were performed using R for Statistical Computing (ver. 3.2.0).

\section{Results}

Se and $\mathrm{Cu}$ were assayed in serum samples taken from patients and control subjects. All micronutrient concentrations are reported as $\mu \mathrm{g} / \mathrm{L}$. Among the control group the 
Table 2. Serum selenium (Se) levels and the frequency of pancreatic cancer

\begin{tabular}{|c|c|c|c|c|c|c|}
\hline Quartile & Se level $(\mu \mathrm{g} / \mathrm{L})$ & Case & Control & OR & p-value & $95 \% \mathrm{CI}$ \\
\hline I & $29.87-56.20$ & 45 & 5 & 41 & $<0.0001$ & $12.693-132.44$ \\
\hline II & $56.52-69.12$ & 32 & 18 & 8.099 & $<0.0001$ & $3.214-20.411$ \\
\hline III & 69.26-79.36 & 14 & 36 & 1.772 & 0.3421 & $0.6853-4.580$ \\
\hline IV & $79.43-122.46$ & 9 & 41 & 1 & - & - \\
\hline
\end{tabular}

OR, odds ratio; CI, confidence interval.

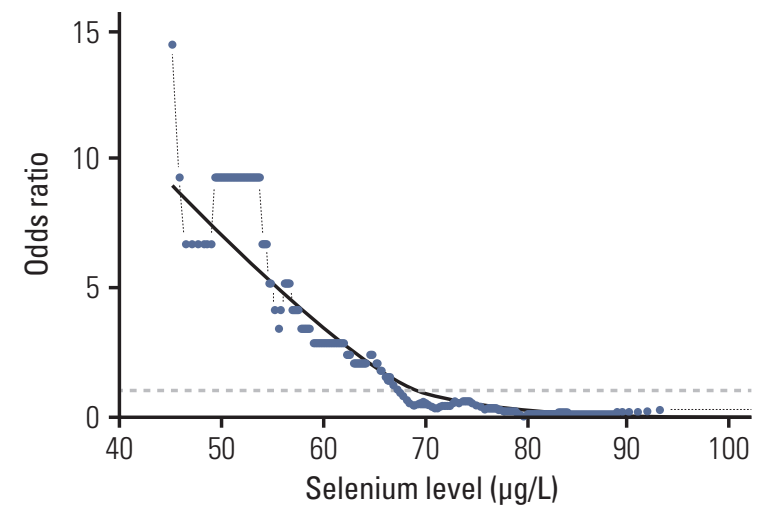

Fig. 1. The probability curve of developing pancreatic cancer (odds ratio) for selenium levels $(\mu \mathrm{g} / \mathrm{L})$ shown for a sliding window approach (window size, 30 observations). Values above that line indicate an increased probability, values below indicate a decreased probability of developing pancreatic cancer. The reference proportion is 1:1 for the whole series (odds ratio 1, dotted grey line). A Lowessregression was applied to these calculated data points to estimate the underlying probability curve. Note that the odds ratio scale is not proportional: e.g., a 10-fold increased probability of developing pancreatic cancer corresponds to odds ratio 10 , while a 10 -fold decreased probability corresponds to odds ratio 0.1 .

average Se level was $76 \mu \mathrm{g} / \mathrm{L}$ (range, 43 to $110 \mu \mathrm{g} / \mathrm{L}$ ); Cu, 1,098 $\mu \mathrm{g} / \mathrm{L}$ (range, 695 to 1,683 $\mu \mathrm{g} / \mathrm{L}$ ). The mean Se level among PaCa patients was $60 \mu \mathrm{g} / \mathrm{L}$ (range, 29 to $122 \mu \mathrm{g} / \mathrm{L}$ ) and the mean $\mathrm{Cu}$ level was 1,432 $\mu \mathrm{g} / \mathrm{L}$ (range, 764 to 2,901 $\mu \mathrm{g} / \mathrm{L})$. In the PaCa group, the mean serum Se level was 59 $\mu \mathrm{g} / \mathrm{L}$ for women (range, 29 to $88 \mu \mathrm{g} / \mathrm{L}$ ), $61 \mu \mathrm{g} / \mathrm{L}$ for men (range, 33 to $122 \mu \mathrm{g} / \mathrm{L}$ ) and $\mathrm{Cu}$ level was 1,524 $\mu \mathrm{g} / \mathrm{L}$ for women (range, 858 to $2,901 \mu \mathrm{g} / \mathrm{L}$ ) and 1,369 $\mu \mathrm{g} / \mathrm{L}$ for men (range, 764 to $2,449 \mu \mathrm{g} / \mathrm{L}$ ). The average Se level among the group of healthy participants analyzed was $77 \mu \mathrm{g} / \mathrm{L}$ for women (range, 43 to $110 \mu \mathrm{g} / \mathrm{L}$ ), $75 \mu \mathrm{g} / \mathrm{L}$ for men (range, 45 to $103 \mu \mathrm{g} / \mathrm{L}$ ) and mean $\mathrm{Cu}$ level was 1,206 $\mu \mathrm{g} / \mathrm{L}$ for women (range, 695 to 1,683 $\mu \mathrm{g} / \mathrm{L}$ ) and 1,039 $\mu \mathrm{g} / \mathrm{L}$ for men (range, 740 to $1,421 \mu \mathrm{g} / \mathrm{L})$. The average concentration of Se in the 480 individuals included in this study was $76 \mu \mathrm{g} / \mathrm{L}$ (range, 42 to $162 \mu \mathrm{g} / \mathrm{L}$ ) and $\mathrm{Cu}$ level was 1,128 $\mu \mathrm{g} / \mathrm{L}$ (range, 605 to $1,972 \mu \mathrm{g} / \mathrm{L})$.

\section{Se levels in PaCa patients compared to control subjects}

When the results were split into quartiles, a significant difference in the frequency of low Se level was observed in the PaCa group compared to the matched control subjects and inversely at the highest levels of Se the control group was significantly different compared to the PaCa patient group (Table 2, Fig. 1). The threshold point of Se concentration was $67,45 \mu \mathrm{g} / \mathrm{L}$ below which an increase in PaCa incidence was observed, the lower levels of Se being associated with greater risk of being diagnosed with $\mathrm{PaCa}$. Comparison of the levels of Se in each quartile showed an association of low serum Se levels with an increased incidence of PaCa. Statistically significant differences in Se concentration were observed in comparison of the quartiles with the lowest serum Se levels (I, II) to the quartile with the largest number of healthy individuals (IV) (OR, 41; $\mathrm{p}<0.0001$ and OR, 8,099; $\mathrm{p}<0.0001$, respectively).

\section{Cu levels in PaCa patients compared to control subjects}

A significant difference was observed between the concentration of $\mathrm{Cu}$ in $\mathrm{PaCa}$ patients compared to control subjects. When divided into quartiles an unequivocal relationship between high $\mathrm{Cu}$ levels and disease was observed whereas few $\mathrm{PaCa}$ patients presented with low $\mathrm{Cu}$ values. In comparison of the quartiles with the highest concentrations of the $\mathrm{Cu}$ ranges (III, IV) with the serum $\mathrm{Cu}$ value in the lowest category, a significant increase in the presence of $\mathrm{PaCa}$ was observed (OR, 4.896; $\mathrm{p}=0.0004$ and OR, 26; $\mathrm{p}<0.0001$, respectively) (Table 3, Fig. 2). The threshold point of $\mathrm{Cu}$ concentration was $1,214.58 \mu \mathrm{g} / \mathrm{L}$ for an increase in PaCa incidence, the higher levels of $\mathrm{Cu}$ being associated with greater risk of being diagnosed with $\mathrm{PaCa}$. There were also a substantial proportion of patients with average to above average levels of $\mathrm{Cu}$. 
Table 3. Incidence of the PaCa and serum copper $(\mathrm{Cu})$ levels in analyzed quartiles

\begin{tabular}{lcccccc} 
Quartile & Cu level $(\mu \mathrm{g} / \mathrm{L})$ & Case & Control & OR & p-value & $95 \%$ CI \\
I & $101.97-1,025.88$ & 11 & 39 & 1 & - & - \\
II & $1,027.88-1,182.28$ & 16 & 34 & 1.668 & 0.3678 & $0.681-4.084$ \\
III & $1,187.60-1,448.68$ & 29 & 21 & 4.896 & 0.0004 & $2.043-11.731$ \\
IV & $1,453.79-2,901.35$ & 44 & 6 & 26 & $<0.0001$ & $8.791-76.897$ \\
\hline
\end{tabular}

$\mathrm{PaCa}$, pancreatic cancer; OR, odds ratio; $\mathrm{CI}$, confidence interval.

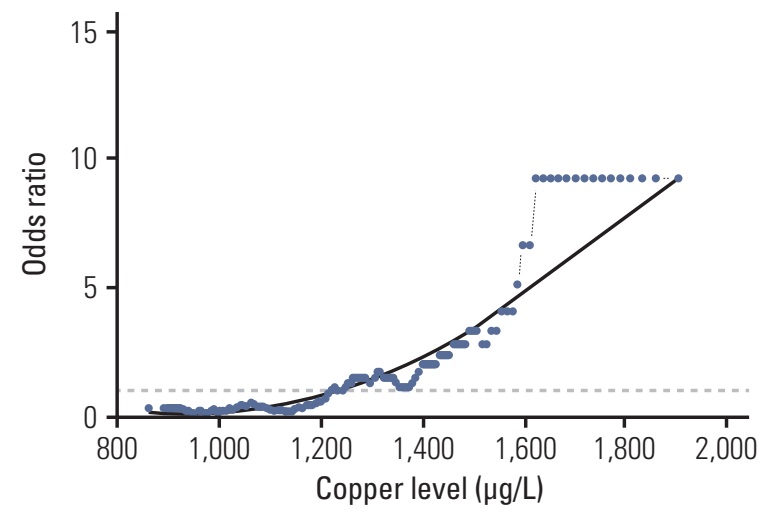

Fig. 2. The probability curve of developing pancreatic cancer (odds ratio) for copper levels $(\mu \mathrm{g} / \mathrm{L}$ ) shown for a sliding window approach (window size, 30 observations). Values above that line indicate an increased probability, values below indicated a decreased probability of developing pancreatic cancer. The reference proportion is 1:1 for the whole series (odds ratio 1, dotted grey line). A Lowess-regression was applied to these calculated data points to estimate the underlying probability curve. Note that the odds ratio scale is not proportional: e.g., a 10-fold increased probability of developing pancreatic cancer corresponds to odds ratio 10 , while a 10 -fold decreased probability corresponds to odds ratio 0.1 .

\section{Cu:Se ratio in PaCa patients compared to control subjects}

Given that the most significant results were observed for $\mathrm{Se}$, followed by $\mathrm{Cu}$, we decided to investigate whether there was any relationship between lower levels of anti-oxidant $\mathrm{Se}$ compared to higher levels of $\mathrm{Cu}$ by examining the $\mathrm{Cu}$ :Se. The average ratios for $\mathrm{Cu}$ :Se assessed from cohorts of 480 participants was 15.01 (range, 7.23 to 34.19).

Examination of the ratio of $\mathrm{Cu}$ :Se showed a much stronger association between patients with $\mathrm{PaCa}$ compared to control subjects (Fig. 3). To determine the effect of high Cu:Se ratio we used the population average for each element as a cutoff. Anything greater than the population average was con- sidered to be associated with disease and anything lower was not. With an increasing Cu:Se ratio we did observe a greater degree of PaCa incidence compared to the lowest quartile (OR, 3.143; $\mathrm{p}=0.0479 ; \mathrm{OR}, 10,127 ; \mathrm{p}<0.0001$; and OR, 691.46; $\mathrm{p}<0.0001$ ) (Table 4). The threshold point of the Cu:Se was 17.97 (Fig. 3) for an increase in cancer occurrence. The greater the ratio of the two micronutrients the greater the probability of being diagnosed with $\mathrm{PaCa}$.

\section{Prognosis of PaCa patients appears dependent on serum Se concentration}

The average time of survival in the study group of 100 patients with $\mathrm{PaCa}$ amounted to 9 months (range, $<1$ months to $>60$ months). In patients with $\mathrm{PaCa}$ in the low range of concentrations of Se (average, $<63.67 \mu \mathrm{g} / \mathrm{L}$ ), the median survival time was 6 months, while in patients with higher levels of Se in the blood (average, $>63.67 \mu \mathrm{g} / \mathrm{L}$ ), the median survival time was 11 months. There appears to be a positive relationship between increasing survival time and Se concentration as depicted by the regression lines, but the observation was not statistically significant (generalized linear model adjusted for age, sex, pack-years, and survival status, $\mathrm{p}=0.0820$ ) (Fig. 4).

\section{Discussion}

The relationship between reactive oxygen species (ROS) and disease is well established and the role of Se is recognized as one of the more important micronutrients in the amelioration of ROS. Systematic studies aimed at understanding the protective effects of anti-oxidants in disease, including $\mathrm{PaCa}$, have been conducted, as this is an attractive model in terms of pointing towards agents that can be administered safely to reduce disease development and/or progression.

Examination of $\mathrm{Cu}$ and particularly $\mathrm{Cu}$ :Se ratio in patients with $\mathrm{PaCa}$ revealed some surprising results. The data presented herein indicate that higher $\mathrm{Cu}$ levels are significantly 
Table 4. Cu:Se ratio and incidence of PaCa

\begin{tabular}{|c|c|c|c|c|c|c|}
\hline Quartile & Cu:Se ratio & Case & Control & OR & p-value & $95 \% \mathrm{CI}$ \\
\hline I & $1.51-14.05$ & 6 & 44 & 1 & - & - \\
\hline II & $14.06-16.72$ & 15 & 35 & 3.143 & 0.0479 & $1.104-8.945$ \\
\hline III & $16.79-24.20$ & 29 & 21 & 10.127 & $<0.0001$ & $3.646-28.126$ \\
\hline IV & $24.44-56.55$ & 50 & 0 & 691.46 & $<0.0001$ & $37.847-12,633$ \\
\hline
\end{tabular}

$\mathrm{Cu}$ :Se, ratio of copper to selenium levels; $\mathrm{PaCa}$, pancreatic cancer; $\mathrm{OR}$, odds ratio; $\mathrm{CI}$, confidence interval.

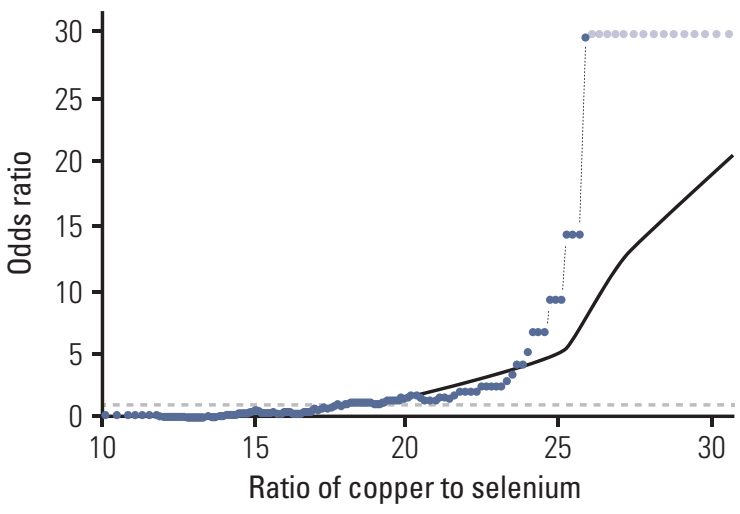

Fig. 3. The probability curve of developing pancreatic cancer (odds ratio) for the ratio of copper to selenium levels shown for a sliding window approach (window size: 30 observations). Values above that line indicate an increased probability, values below indicate a decrease probability of developing pancreatic cancer. The reference proportion is 1:1 for the whole series (odds ratio 1, dotted grey line). A lowess-regreesion was applied to these calculated data points to estimate the underlying probability curve. Note that the odds ratio scale is not proportional: e.g., a 10-fold increased probability of developing pancreatic cancer corresponds to odds ratio 10, while a 10-fold decreased probability corresponds to odds ratio 0.1 . For highest proportions of copper to selenium, where there are no controls, just cases, for the overlapping windows odds ratio was conservatively estimated to be the same as the last calculated odds ratio. Such odds ratios were marked with a grey color in the graphic to avoid confusion.

more common in patients with $\mathrm{PaCa}$ compared to healthy age-matched control subjects. A recent genome-wide association study demonstrated an unequivocal association of SELENBP1 (selenium binding protein 1, a key protein involved in blood $\mathrm{Cu}$ metabolism), with Se metabolism, however it has not been associated with other trace elements [16]. The result of this study suggests that there is a relationship between $\mathrm{Cu}$ and $\mathrm{Se}$, the precise nature of which remains to be described. For consideration of any potential relationship between $\mathrm{Cu}$, Se, and $\mathrm{PaCa}$, we examined the ratio of $\mathrm{Cu}$ :Se and found an even greater association between higher $\mathrm{Cu}$ to Se ratios and cancer than that observed for only higher $\mathrm{Cu}$ levels. This result suggests that there is an association between $\mathrm{Cu}$ and Se which may be mediated by the protein product of SELENBP1. Currently little is known about this protein and it awaits further characterization of its role beyond Se binding.

In general, little is known about the interaction between Se and $\mathrm{Cu}$ at the molecular level. Perhaps common ground in the relationship between the two trace elements is the interaction between the changes among the so-called oxidative stress genes, proteins encoded by them and trace elements such as $\mathrm{Cu}$, Se, or $\mathrm{Zn}$. Overproduction of reactive oxygen and nitrogen species and oxidative stress have been implicated in the pathogenesis of $\mathrm{PaCa}$ [17]. Reactive oxygen and nitrogen species are generated during endogenous oxidative stress that is linked to the pancreatic renin-angiotensin system [18] or exogenous oxidative stress caused by environmental or lifestyle-related xenobiotics, which is allied with the detoxification system [19].

The inverse association between Se concentration and $\mathrm{PaCa}$ incidence is well established [20] and suggests that Se plays a significant role in ameliorating the effects of ROS. The results of studies conducted in Spain on a patient group of similar size $(n=118)$ showed an association of high concentrations of toenail Se with the occurrence of exocrine $\mathrm{PaCa}$ (OR, 0.05; 95\% CI, 0.02 to $0.15 ; \mathrm{p}$ (trend) $=8 \times 10(-11))$ [20]. The association between $\mathrm{PaCa}$ and serum Se was also observed in an earlier small study (22 cases of PaCa, 44 matched controls) conducted in the United States. In this report, the association between incidence of $\mathrm{PaCa}$ and serum Se levels was significant when the data were analyzed as a whole, but its effect was observed principally in men (OR, 12.5; 95\% CI, 1.78 to 84.0$)$ and almost none among the women (OR, 1.2; CI, 0.56 to 2.53). Lower mean serum levels of Se were observed in cases $(1.29 \pm 0.04 \mu \mathrm{mol} / \mathrm{L})$ than in control subjects $(1.42 \pm 0.03$ $\mu \mathrm{mol} / \mathrm{L})$ and this difference was significant $(0.01<\mathrm{p}<0.025)$ 


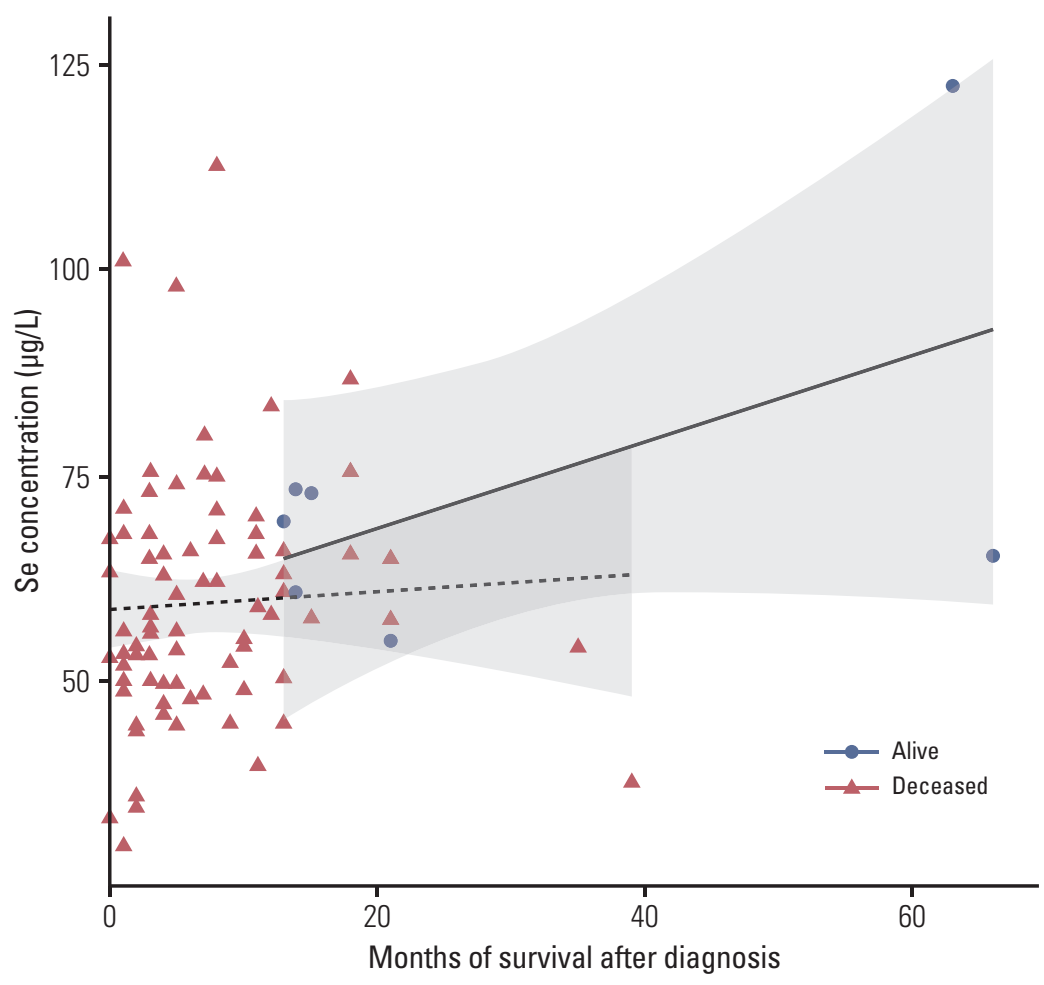

Fig. 4. The relationship between survival time and selenium (Se) blood plasma level among pancreatic cancer patients (separated for patients still alive and already deceased) is depicted as two regression lines (with confidence intervals shown in gray). Higher Se values seem to be associated with increasing survival time; however, this association is not significant (generalized linear model adjusted for age, sex, pack-years, and survival status, $\mathrm{p}=0.0820$ ).

[21]. A non-significant difference in serum Se level was observed in an Iranian study conducted among $80 \mathrm{PaCa}$ patients (cases, $9.25 \mu \mathrm{g} / \mathrm{dL}$; controls, $10.06 \mu \mathrm{g} / \mathrm{dL}$ ) [22]. Our results are consistent with the observation that a low level of $\mathrm{Se}$ is a characteristic of patients with $\mathrm{PaCa}$.

The role of Se in protecting against other diseases of the pancreas remains controversial with some studies suggesting a protective effect and others suggest at best no effect and possibly an increased risk of disease [13]. Of note, in many studies conducted outside of Poland there are relatively high base-line levels of Se, which may render any supplementation at best useless but more likely harmful.

Particularly intriguing is our finding that high $\mathrm{Cu}$ levels appear to be associated with PaCa. This finding, which is inversely related to Se levels, suggests that high Cu:Se ratios may result in higher levels of ROS that impact on the risk of developing and/or progression of $\mathrm{PaCa}$. $\mathrm{Cu}$ is associated with ROS production [23] and $\mathrm{Se}$, as a selenoprotein, acts to mitigate the effects of excessive ROS. Given that the Cu:Se was consistently greater in PaCa patients compared to agematched control subjects suggests that the Cu:Se may be associated with high levels of ROS exposure that predispose susceptible patients to the development and/or progression of disease. This evidence ties in with recent studies examining the mutational landscape in $\mathrm{PaCa}$, where there appears to be a breakdown in DNA repair making pancreatic cells exquisitely sensitive to DNA damaging agents, particularly ROS [1].

So far, a statistically significant increase in serum Cu level among patients suffering from $\mathrm{PaCa}$ was reported in a casecontrol study conducted among $50 \mathrm{PaCa}$ patients with Greek origin. In this study, the average serum $\mathrm{Cu}$ level among 32 male PaCa patients was $171 \mathrm{~g} / 100 \mathrm{~mL}$ and $137 \mathrm{~g} / 100 \mathrm{~mL}$ among 34 healthy men. Among 18 women with PaCa the average serum $\mathrm{Cu}$ level was $165 \mathrm{~g} / 100 \mathrm{~mL}$ and $137 \mathrm{~g} / 100$ $\mathrm{mL}$ among 29 healthy women [24]. In these studies, the authors probably rightly point to the potential diagnostic value of this observation. A non-significant difference in serum Cu levels (cases, $87.14 \mu \mathrm{g} / \mathrm{dL}$; controls, $91.17 \mu \mathrm{g} / \mathrm{dL}$ ) was observed in an Iranian study conducted among $80 \mathrm{PaCa}$ individuals with $\mathrm{PaCa}$ and group of 100 healthy participants [22]. In light of our observations, the results suggest that determination of both the level of Se and $\mathrm{Cu}$ could be a good supplementary laboratory test for the current diagnosis of 
$\mathrm{PaCa}$. This report also shows a high serum $\mathrm{Cu}$ level as a potential factor in development and / or progression of $\mathrm{PaCa}$ in the Polish population.

Thus far, one prospective study showed an association of high levels of $\mathrm{Se}$, vitamins $\mathrm{C}$ and $\mathrm{E}$ with a reduced risk of PaCa (HR, 0.33; $\mathrm{p}<0.05)$. This prospective study demonstrated that higher intakes of Se (and vitamin $\mathrm{E}$ ), reduced the risk of PaCa by at least $40 \%$ [25].

Low levels of Se and high levels of $\mathrm{Cu}$ observed in our retrospective study of samples of $\mathrm{PaCa}$ patients cannot be treated as a marker for the risk of PaCa. When the serum Se level is examined in patients with newly diagnosed cancers the results can be influenced by the tumor itself. Therefore, retrospective case-control studies are not suitable to conclude that low Se levels are the cause of disease, although such studies can be valuable in determining whether Se levels may be used as a useful marker in the selection of patients for disease surveillance. The level of these micronutrients should rather be regarded as PaCa patients' lab status not the causal explanation for cancer development. As we observed, a low level of Se/high $\mathrm{Cu}$ in patients with $\mathrm{PaCa}$ can be considered as a potential diagnostic marker indicative of the neoplastic process and not as a risk marker or a direct cause of cancer. However, it cannot exclude the possibility that micronutrients (Se, $\mathrm{Cu}$ ) lab status of $\mathrm{PaCa}$ patients may affect the development of $\mathrm{PaCa}$. In our study, we observed a longer survival (on the border of statistical significance) for patients with $\mathrm{PaCa}$ and a high level of Se compared to subjects with cancer of the pancreas and low level of Se (medium, 11 months vs. 6 months). Therefore, it cannot be excluded that the level of Se may be a prognostic marker in $\mathrm{PaCa}$. The level of Se was far from optimal among the PaCa patients we examined, however, a longer survival time was observed even in patients whose levels of Se showed higher values. This observation must be verified in a larger series of PaCa cases, but if related to the results of prospective studies, it is not surprising. Data from meta-analysis of 49 prospective studies have also confirmed a reduction in cancer mortality by $45 \%$ in persons with an optimized Se concentration [11]. In our retrospective study, we observed that $\mathrm{PaCa}$ prolonged survival only in patients with higher levels of Se, but this observation is part of an overall favorable view of the importance of Se in the prevention of cancer in general. However, these data can suggest the potentially preferred meaning of chemoprevention of Se in populations with low levels of Se, which include the Polish population (mean level of Se in serum $70 \mu \mathrm{g} / \mathrm{L}$ ).

There are several limitations to our study. Perhaps the most important limitation of our case-control study is that the $\mathrm{Se}$ and $\mathrm{Cu}$ and copper measurements for cases were made after the diagnosis of $\mathrm{PaCa}$, although before therapy. It is possible that the low levels of Se and high levels of $\mathrm{Cu}$ detected could be a consequence of disease. If this is the case, then a low Se/high Cu level could potentially be a marker of progression rather than just a risk factor. The sample size in our study is relatively small but the associations for Se and $\mathrm{Cu}$ levels were strong and highly significant. The cases and controls were matched for smoking status and it is therefore unlikely that the association could be confounded by smoking, but it is possible that another confounding variable could introduce bias. Se levels could be affected by arsenic level, which is known to be present in cigarette smoke. However, since the cases have been matched with controls for smoking status (expressed in pack-years) and the arsenic content of the cigarettes is controlled by World Health Organization (WHO) guidelines, the effects have been mitigated as much as possible.

\section{Conclusion}

This retrospective study suggests that low levels of Se and high levels of $\mathrm{Cu}$ may affect $\mathrm{PaCa}$ development. The results of our retrospective study support an inverse association of lower levels of Se and an increased probability of PaCa and indicate an association between higher serum $\mathrm{Cu}$ levels with disease. The determination of $\mathrm{Se}$ and $\mathrm{Cu}$ in the blood serum can complement conventional procedures used in diagnosis of $\mathrm{PaCa}$ as an additional laboratory marker. In addition, it appears that a higher level of Se is associated with longer survival in patients with $\mathrm{PaCa}$. While our findings need to be replicated in other independent studies, they suggest a role of $\mathrm{Se}$ and $\mathrm{Cu}$ as markers in diagnosis of $\mathrm{PaCa}$ and possible development. Unquestionably, prospective cohort studies will be required to elucidate the use of Se and $\mathrm{Cu}$ measurements as markers of risk of PaCas. Currently it seems that determining the level of $\mathrm{Se}$ and $\mathrm{Cu}$ can be a marker for selection for control examinations in surveillance as a valuable complement to existing diagnostic procedures.

\section{Conflicts of Interest}

Conflict of interest relevant to this article was not reported. 


\section{Acknowledgments}

Authors thank Ms. Ewa Putresza for excellent technical assistance. This work was supported in part by National Sci- ence Centre (NCN) grant UMO-2011/03/N/NZ2/01539, part-financed by own funds of Read-Gene S.A. The funders had no role in study design, data collection and analysis, decision to publish, or preparation of the manuscript.

\section{References}

1. Waddell N, Pajic M, Patch AM, Chang DK, Kassahn KS, Bailey $\mathrm{P}$, et al. Whole genomes redefine the mutational landscape of pancreatic cancer. Nature. 2015;518:495-501.

2. Silverman DT, Dunn JA, Hoover RN, Schiffman M, Lillemoe $\mathrm{KD}$, Schoenberg JB, et al. Cigarette smoking and pancreas cancer: a case-control study based on direct interviews. J Natl Cancer Inst. 1994;86:1510-6.

3. Li D, Xie K, Wolff R, Abbruzzese JL. Pancreatic cancer. Lancet. 2004;363:1049-57.

4. Goggins M, Schutte M, Lu J, Moskaluk CA, Weinstein CL, Petersen GM, et al. Germline BRCA2 gene mutations in patients with apparently sporadic pancreatic carcinomas. Cancer Res. 1996;56:5360-4.

5. Klein AP, Lindstrom S, Mendelsohn JB, Steplowski E, Arslan AA, Bueno-de-Mesquita $\mathrm{HB}$, et al. An absolute risk model to identify individuals at elevated risk for pancreatic cancer in the general population. PLoS One. 2013;8:e72311.

6. Amundadottir L, Kraft P, Stolzenberg-Solomon RZ, Fuchs CS, Petersen GM, Arslan AA, et al. Genome-wide association study identifies variants in the $\mathrm{ABO}$ locus associated with susceptibility to pancreatic cancer. Nat Genet. 2009;41:986-90.

7. Petersen GM, Amundadottir L, Fuchs CS, Kraft P, Stolzenberg-Solomon RZ, Jacobs KB, et al. A genome-wide association study identifies pancreatic cancer susceptibility loci on chromosomes 13q22.1, 1q32.1 and 5p15.33. Nat Genet. 2010;42: 224-8.

8. Klein AP, Brune KA, Petersen GM, Goggins M, Tersmette AC, Offerhaus GJ, et al. Prospective risk of pancreatic cancer in familial pancreatic cancer kindreds. Cancer Res. 2004;64: 2634-8.

9. Chan S, Gerson B, Subramaniam S. The role of copper, molybdenum, selenium, and zinc in nutrition and health. Clin Lab Med. 1998;18:673-85.

10. Duffield-Lillico AJ, Reid ME, Turnbull BW, Combs Gf Jr, Slate $\mathrm{EH}$, Fischbach LA, et al. Baseline characteristics and the effect of selenium supplementation on cancer incidence in a randomized clinical trial: a summary report of the Nutritional Prevention of Cancer Trial. Cancer Epidemiol Biomarkers Prev. 2002;11:630-9.

11. Dennert G, Zwahlen M, Brinkman M, Vinceti M, Zeegers MP, Horneber M. Selenium for preventing cancer. Cochrane Database Syst Rev. 2011;(5):CD005195.

12. Rayman MP. Selenium and human health. Lancet. 2012;379:
1256-68.

13. Rayman MP, Stranges S. Epidemiology of selenium and type 2 diabetes: can we make sense of it? Free Radic Biol Med. 2013;65:1557-64.

14. Linder MC, Hazegh-Azam M. Copper biochemistry and molecular biology. Am J Clin Nutr. 1996;63:797S-811S.

15. Kodydkova J, Vavrova L, Stankova B, Macasek J, Krechler T, Zak A. Antioxidant status and oxidative stress markers in pancreatic cancer and chronic pancreatitis. Pancreas. 2013;42: 614-21.

16. Evans DM, Zhu G, Dy V, Heath AC, Madden PA, Kemp JP, et al. Genome-wide association study identifies loci affecting blood copper, selenium and zinc. Hum Mol Genet. 2013;22: 3998-4006.

17. Leung PS, Chan YC. Role of oxidative stress in pancreatic inflammation. Antioxid Redox Signal. 2009;11:135-65.

18. Skipworth JR, Szabadkai G, Olde Damink SW, Leung PS, Humphries SE, Montgomery HE. Review article: pancreatic renin-angiotensin systems in health and disease. Aliment Pharmacol Ther. 2011;34:840-52.

19. Tandon RK, Garg PK. Oxidative stress in chronic pancreatitis: pathophysiological relevance and management. Antioxid Redox Signal. 2011;15:2757-66.

20. Amaral AF, Porta M, Silverman DT, Milne RL, Kogevinas M, Rothman N, et al. Pancreatic cancer risk and levels of trace elements. Gut. 2012;61:1583-8.

21. Burney PG, Comstock GW, Morris JS. Serologic precursors of cancer: serum micronutrients and the subsequent risk of pancreatic cancer. Am J Clin Nutr. 1989;49:895-900.

22. Farzin L, Moassesi ME, Sajadi F, Faghih MA. Evaluation of trace elements in pancreatic cancer patients in Iran. Middle East J Cancer. 2013;4:79-86.

23. Bandyopadhyay U, Das D, Banerjee RK. Reactive oxygen species: oxidative damage and pathogenesis. Curr Sci. 1999; 77:658-66.

24. Manousos O, Trichopoulos D, Koutselinis A, Papadimitriou C, Polychronopoulou A, Zavitsanos X. Epidemiologic characteristics and trace elements in pancreatic cancer in Greece. Cancer Detect Prev. 1981;4:439-42.

25. Banim PJ, Luben R, McTaggart A, Welch A, Wareham N, Khaw KT, et al. Dietary antioxidants and the aetiology of pancreatic cancer: a cohort study using data from food diaries and biomarkers. Gut. 2013;62:1489-96. 